\title{
HUBUNGAN ANTARA KEPERCAYAAN DAN KETERPAPARAN INFORMASI DENGAN PENGETAHUAN DAN SIKAP TERHADAP PERAWATAN METODE KANGURU PADA BIDAN DI KABUPATEN MUSI RAWAS SUMATERA SELATAN TAHUN 2016
}

\author{
Siti Mudiyah ${ }^{1}$, Hadi Pratomo², Besral ${ }^{3}$
}

\begin{abstract}
Background: Infant and Neonatal mortality in Musi Rawas District is the highest in Southern Sumatera in 2014. Implementation of kangaroo mother care as Low Birth Weight treatment is still limited in the provincial general hospital Dr. Mohammad Hoesin, Palembang. At the present time, midwives as maternal and child health service provider, can access many information including Kangaroo Mother Care from various media.
\end{abstract}

Objectives: This study aimed to analyze the relationship between belief in the myth of LBW care and exposure information with the knowledge and attitudes toward kangaroo mother care on midwives in Musi Rawas District of Southern Sumatra 2016.

Method: Cross sectional study design used on 197 midwives with purposive sampling.

Result and Discussion: The results showed that midwives who have relatifely good knowledge about KMC As much as 50,8\% and having relatively positive attitude towards KMC as much as $40.1 \%$. There are a significant relationship between belief of $L B W$ care $(\rho=0,001 ; O R: 3,1 ; 95 \% \mathrm{Cl}: 1,6-5,8)$, exposure information from scientific media ( $\rho=0,039$; OR: 2,4; $95 \% \mathrm{Cl}: 1,0-5,4)$, training $(\rho=0,001 ; 0 R: 3.5 ; 95 \% \mathrm{Cl}$ : $1.7-7,5)$ with knowledge about KMC on midwives.

Conclusion: A significant relationship also demonstrated between exposure information from training with attitude towards $K M C$ on midwives ( $\rho=0,003 ;$ OR: 2,8; $95 \% \mathrm{Cl}: 1,4-5,6)$. Improving quality of the midwives in Kangaroo Mother Care is very important so midwives can provide counseling, information, and education to mother since detected with LBW.

Keywords: Kangaroo Mother Care, Midwife, Belief, Attitude, Knowledge of KMC

\begin{abstract}
ABSTRAK
Latar Belakang : Jumlah kematian bayi dan neonatus di Kabupaten Musi Rawas merupakan tertinggi di Provinsi Sumatera Selatan pada tahun 2016. Implementasi perawatan metode kanguru sebagai perawatan BBLR masih terbatas di RSUP Dr. Mohammad Hoesin, Kota Palembang. Di masa sekarang ini, bidan sebagai tenaga kesehatan penyedia layanan kesehatan ibu dan anak, dapat mengakses berbagai macam informasi dari berbagai media termasuk informasi mengenai PMK.

Tujuan: Penelitian ini bertujuan untuk menganalisis hubungan kepercayaan dan keterpaparan informasi dengan pengetahuan dan sikap terhadap Perawatan Metode Kanguru pada bidan di Kabupaten Musi Rawas Sumatera Selatan Tahun 2016.
\end{abstract}

Metode : Desain penelitian cross sectional pada 197 bidan dengan purposive sampling.

\footnotetext{
Mahasiswa Magister Fakultas Kesehatan Masyarakat Universitas Indonesia

Departemen Promosi Kesehatan dan Ilmu Perilaku Fakultas Kesehatan Masyarakat Universitas Indonesia

3 Departemen Biostatistik Fakultas Kesehatan Masyarakat Universitas Indonesia

Kampus Baru UI Depok 16424 Indonesia

email: mudiyahsiti1991@gmail.com
} 
Hasil dan Pembahasan: penelitian menunjukkan bahwa bidan yang mempunyai pengetahuan yang baik tentang PMK sebanyak 39,6\% dan yang mempunyai sikap positif terhadap PMK sebanyak $89,3 \%$. Terdapat hubungan yang signifikan antara kepercayaan ( $\rho=0,027$; OR: 2,4; $95 \% \mathrm{Cl}: 1,1-5,2)$, keterpaparan informasi dari media ilmiah ( $\rho=0,017$; OR: 2,$9 ; 95 \% \mathrm{Cl}: 1,2-6,9)$, dan pelatihan PMK $(\rho=0,001 ;$ OR: 3,$3 ; 95 \% \mathrm{Cl}: 1,6$ $-6,7)$ dengan pengetahuan tentang PMK pada bidan.

Kesimpulan: Hubungan yang signifikan juga ditunjukkan antara keterpaparan informasi dari pelatihan PMK dengan sikap terhadap PMK pada bidan ( $\rho=0,049 ;$ OR: 3,8; $95 \% \mathrm{Cl}: 1,0-14,7)$. Upaya peningkatan pengetahuan bidan pada perawatan metode kanguru sangat penting agar bidan dapat memberikan KIE kepada ibu sejak dideteksi hamil dengan BBLR.

Kata Kunci: Perawatan Metode Kanguru, Bidan, Kepercayaan, Sikap, Pengetahuan.

\section{Pendahuluan}

Angka Kematian Bayi (AKB) merupakan indikator dalam menilai keberhasilan pelayanan kesehatan dan pembangunan negara di bidang kesehatan. ${ }^{1}$ Data WHO (2016) menunjukkan angka kematian bayi di dunia pada tahun 2015 sejumlah 31,7 kematian per 1000 kelahiran hidup, sedangkan angka kematian bayi di Asia Tenggara sejumlah 34 kematian per 1000 kelahiran hidup. Angka ini menunjukkan angka kematian bayi di Asia Tenggara masih lebih tinggi dari rata-rata AKB di dunia ${ }^{2}$. Angka Kematian Bayi (AKB) di Indonesia juga masih tinggi. Menurut SDKI (2012), AKB di Indonesia pada tahun 2012 adalah 32 kematian per 1000 kelahiran hidup, padahal Indonesia menargetkan 23 kematian per 1000 kelahiran hidup pada tahun 2015. Angka kematian neonatus di Indonesia juga masih stagnan di angka 19 kematian per 1000 kelahiran hidup pada tahun 2007 dan 2012. ${ }^{3}$

Pada tahun 2014 terdapat 114 kematian bayi di Provinsi Sumatera Selatan kasus dengan kasus tertinggi di Kabupaten Musi Rawas yaitu 25 kasus. Jumlah kematian neonatus di Provinsi Sumatera Selatan sampai dengan bulan Desember 2014 juga mencapai 629 kasus dengan kasus kematian neonatus tertinggi berada di Kabupaten Musi Rawas dengan 84 kasus. ${ }^{4}$ Artinya, pada tahun 2014 Kabupaten Musi Rawas mengalami jumlah kematian bayi dan neonatus tertinggi di Provinsi Sumatera Selatan.

Penyebab terbanyak kematian neonatus adalah prematuritas dan Bayi Berat Lahir Rendah (BLBR), yaitu sebesar $30 \%$ dari seluruh kematian neonates. ${ }^{5,6}$ Setiap tahun di dunia diperkirakan lahir sekitar 20 juta BBLR, dan 95\% terjadi di negara-negara berkembang. ${ }^{7,8}$ Berdasarkan data SDKI (2012) di Indonesia terdapat 7,3\% bayi yang dilahirkan dengan berat badan di bawah $2,5 \mathrm{~kg}^{3}$. Di Kabupaten Musi Rawas, jumlah kasus BBLR sebanyak 3,3\% dari seluruh bayi yang dilahirkan. ${ }^{9}$

Perawatan BBLR yang berkualitas dapat menurunkan kematian neonatus. Selama ini perawatan BBLR identik dengan perawatan menggunakan inkubator dan penempatan di ruang Neonatologi Intensive Care Unit (NICU). ${ }^{1}$ Sebuah inovasi perawatan BBLR yang dapat memberikan manfaat lebih daripada inkubator yaitu Perawatan Metode Kanguru (PMK). ${ }^{8,10,11}$ Perawatan Metode Kanguru dapat mencegah setengah dari kematian neonatal dengan berat lahir di bawah 2000 gram. ${ }^{1,12,13}$

Implementasi PMK sebagai perawatan pada BBLR masih terbatas. Di Indonesia, hanya ada 21 rumah sakit yang melaporkan telah mengimplementasikan PMK termasuk RSUP Dr. Mohammad Hoesin yang merupakan satu- 
satunya rumah sakit di Provinsi Sumatera Selatan yang telah mengimplementasikan PMK. ${ }^{13}$ Penelitian Sembiring, menunjukkan bahwa $46,67 \%$ tenaga kesehatan di ruang perinatologi RSUD Ade $M$ Djoen Sintang yang mempunyai pengetahuan kurang baik tentang PMK dan hanya ada $53,33 \%$ yang mempunyai pengetahuan cukup. $^{14}$

Di masa sekarang ini, perkembangan dunia informasi global menunjukkan peningkatan yang sangat cepat. Terbukanya akses informasi memungkinkan setiap orang untuk mengakses berbagai macam informasi dari berbagai media. Informasi PMK pun dapat dengan mudah diperoleh dari media massa seperti media elektronik, media cetak, dan juga media sosial. Keterpaparan seseorang akan informasi PMK akan mempengaruhi pengetahuan dan sikapnya terhadap PMK. Selain itu, faktor lingkungan sosial seperti kepercayaan terhadap perawatan BBLR juga akan mempengaruhi pengetahuan dan sikap terhadap PMK. Oleh karena itu, penelitian ini bertujuan untuk menganalisis hubungan antara kepercayaan dan keterpaparan informasi dengan pengetahuan dan sikap terhadap perawatan metode kanguru pada bidan di Kabupaten Musi Rawas Sumatera Selatan tahun 2016.

\section{Metode Penelitian}

Penelitian ini menggunakan desain penelitian cross sectional. Populasinya adalah seluruh bidan di Kabupaten Musi Rawas Sumatera Selatan tahun 2016. Sampel yang diambil adalah bidan yang memenuhi kriteria inklusi, yaitu bidan yang menjadi anggota IBI (Ikatan Bidan Indonesia), hadir di seminar "Filosofi Terkini Perawatan Bayi Prematur dan BBLR" yang dilaksanakan oleh pengurus IBI Cabang Musi Rawas Sumatera Selatan, dan bersedia mengisi kuisioner penelitian.

Pengambilan sampel menggunakan quota sampling dan didapatkan jumlah sampel 197 responden. Teknik pengumpulan data menggunakan kuesioner yang diadaptasi dari studi pengembangan rujukan BBLR dengan perawatan metode kanguru sesudah pulang dari rumah sakit oleh Hadi Pratomo dkk dan telah dilakukan uji validitas dan reliabilitas. Pengumpulan data dalam penelitian ini yaitu dengan membagikan kuesioner secara langsung kepada bidan yang hadir sebelum seminar dimulai. Sebelum pengumpulan data, responden menandatangani lembar informed consent.

\section{Hasil Penelitian}

Karakteristik individu bidan di Kabupaten Musi Rawas Sumatera Selatan (tabel 1). Pada tabel 1 menunjukkan bahwa rata-rata umur responden adalah 29 tahun $(95 \% \mathrm{Cl} 28-30$ tahun) dengan standar deviasi 7 tahun. Umur termuda 21 tahun dan umur tertua 49 tahun. 
Tabel 1 Karakteristik Individu Bidan di Kabupaten Musi Rawas Sumatera Selatan Tahun 2016 (n = 197)

\begin{tabular}{|c|c|c|c|}
\hline Variabel & \multicolumn{2}{|c|}{$\mathbf{n}$} & $\%$ \\
\hline \multicolumn{4}{|l|}{ Umur } \\
\hline Minimal-Maksimal & \multicolumn{3}{|c|}{$21-49$ tahun } \\
\hline Rata-rata & \multicolumn{3}{|c|}{29 tahun } \\
\hline Standar Deviasi & \multicolumn{3}{|c|}{7 tahun } \\
\hline $95 \% \mathrm{Cl}$ & \multicolumn{3}{|c|}{ 28-30 tahun } \\
\hline \multicolumn{4}{|l|}{ Pendidikan Terakhir } \\
\hline Diploma 1 & \multicolumn{2}{|l|}{2} & 1,0 \\
\hline Diploma 3 & \multicolumn{2}{|l|}{176} & 89,3 \\
\hline Diploma 4 & \multicolumn{2}{|l|}{11} & 5,6 \\
\hline Sarjana 1 & \multicolumn{2}{|l|}{8} & 4,1 \\
\hline \multicolumn{4}{|l|}{ Masa Kerja } \\
\hline Minimal-Maksimal & \multicolumn{3}{|c|}{$1-27$ tahun } \\
\hline Rata-rata & \multicolumn{3}{|c|}{8 tahun } \\
\hline Standar Deviasi & \multicolumn{3}{|c|}{6 tahun } \\
\hline $95 \% \mathrm{Cl}$ & \multicolumn{3}{|c|}{$7-9$ tahun } \\
\hline \multicolumn{4}{|l|}{ Pengalaman Melahirkan BBLR } \\
\hline Tidak Pernah & \multicolumn{2}{|l|}{115} & 58,4 \\
\hline Pernah & \multicolumn{2}{|l|}{82} & 41,6 \\
\hline \multicolumn{4}{|l|}{ Pengalaman Menolong Persalinan BBLR } \\
\hline Tidak Pernah & \multicolumn{2}{|l|}{83} & 42,1 \\
\hline Pernah & \multicolumn{2}{|l|}{114} & 57,9 \\
\hline Kepemilikan Media Elektronik & 110 & 55,8 & 55,8 \\
\hline Memiliki $\leq 2$ media elektronik & 87 & 44,2 & 44,2 \\
\hline \multicolumn{4}{|l|}{ Memiliki > 2 media elektronik } \\
\hline Kepemilikan Meda Sosial & 141 & 71,6 & 71,6 \\
\hline Memiliki $\leq 2$ media sosial & 56 & 28,4 & 28,4 \\
\hline \multicolumn{4}{|l|}{ Memiliki > 2 media sosial } \\
\hline Kepemilikan Media Cetak & 138 & 70,1 & 70,1 \\
\hline Tidak memiliki langganan media cetak & 59 & 29,9 & 29,9 \\
\hline Memiliki langganan media cetak & 110 & 55,8 & 55,8 \\
\hline
\end{tabular}

Tingkat pendidikan terakhir responden paling banyak adalah Diploma 3 (89,3\%), namun masih ada responden yang berpendidikan terakhir Diploma 1 (1,0 \%). Rata-rata masa kerja bidan adalah 8 tahun ( $95 \% \mathrm{Cl} 7-9$ tahun) dengan standar deviasi 6 tahun. Masa kerja responden yang paling sebentar adalah 1 tahun dan yang paling lama sudah 27 tahun. Responden yang pernah melahirkan BBLR sebanyak 41,6\%, sedangkan responden yang mempunyai pengalaman menolong persalinan BBLR sebanyak $57,9 \%$. 
Pada tabel 1 juga menunjukkan bahwa responden yang memiliki $>2$ media elektronik sebanyak 44,2\%. Hampir seluruh responden mempunyai televisi (98,5\%). Media elektronik yang paling sedikit dimiliki oleh responden adalah radio (28,9\%). Responden yang memiliki $>2$ media sosial yaitu sebanyak 28,4\%. Media sosial yang paling banyak dimiliki responden adalah facebook $(83,2 \%)$, selanjutnya line $(31,0 \%)$, dan instagram $(29,4 \%)$. Responden yang memiliki langganan media cetak sebanyak 29,9\%. Responden paling banyak yang memiliki langganan koran $(27,4 \%)$ dan yang paling sedikit dimiliki adalah tabloid (2,5\%).

Kepercayaan terhadap perawatan BBLR pada bidan di Kabupaten Musi Rawas Sumatera Selatan dapat dilihat pada tabel 2. Perawatan BBLR yang paling banyak dipercayai oleh responden $(80,7 \%)$ adalah BBLR perlu diberikan bedong yang lebih tebal jika terjadi hipotermi. Perawatan BBLR selanjutnya yang dipercayai oleh lebih dari $65,0 \%$ responden adalah perawatan BBLR bisa dilakukan dengan penggunaan botol air panas di dekat bayi $(71,6 \%)$ dan semua BBLR harus di rawat di ruang perawatan khusus (NICU) sampai berat badannya normal $(66,5 \%)$.

Kisaran jumlah skor kepercayaan terhadap perawatan BBLR adalah 10 sampai 40. Ratarata jumlah skor kepercayaan pada responden adalah 24,17 (95\% Cl 23,59 - 24,76) dengan standar deviasi 4,15. Skor terendah 10 dan skor tertinggi 38. Kepercayaan terhadap perawatan BBLR dikategorikan berdasarkan presentase jumlah skor kepercayaan (70\%). Pada tabel 3 menunjukkan bahwa sebanyak $80,2 \%$ responden yang kepercayaan terhadap perawatan BBLR kurang baik.

Tabel 2 Kepercayaan terhadap Perawatan BBLR pada Bidan di Kabupaten Musi Rawas Sumatera Selatan Tahun 2016 ( $\mathrm{n}=197)$

\begin{tabular}{|l|c|c|}
\hline \multicolumn{1}{|c|}{ Pernyataan Mitos } & Percaya (\%) & Kurang Percaya(\%) \\
\hline $\begin{array}{l}\text { BBLR membutuhkan susu formula khusus untuk mencukupi pertumbu- } \\
\text { hannya. }\end{array}$ & 61,4 & 38,6 \\
$\begin{array}{l}\text { Perawatan BBLR di rumah yaitu dengan diberikan lampu 100 watt di atas } \\
\text { bayi. }\end{array}$ & 56,9 & 43,1 \\
Semua BBLR tidak bisa menghisap ASI dengan baik. & 27,4 & 72,6 \\
$\begin{array}{l}\text { BBLR perlu minum dari botol susu supaya belajar menghisap } \\
\text { Semua BBLR harus di rawat di ruang perawatan khusus (NICU) sampai } \\
\text { berat badannya normal. }\end{array}$ & 32,5 & 67,5 \\
$\begin{array}{l}\text { Perawatan BBLR bisa dilakukan dengan penggunaan botol air panas di } \\
\text { dekat bayi. }\end{array}$ & 71,6 & 33,5 \\
$\begin{array}{l}\text { Semua BBLR perlu dimasukkan ke dalam inkubator. } \\
\text { BBLR belum dapat menempel pada payudara bila berusia <34 minggu. } \\
\text { Perawatan BBLR juga bisa dilakukan dengan memandikan bayi dengan } \\
\text { minyak kelapa. }\end{array}$ & 64,0 & 28,4 \\
BBLR perlu diberikan bedong yang lebih tebal jika terjadi hipotermi & 44,2 & 36,0 \\
\hline
\end{tabular}


Pada tabel 3 menunjukkan bahwa responden paling banyak terpapar informasi PMK dari media elektronik sebanyak $67,0 \%$, sedangkan responden yang pernah mengikuti pelatihan PMK hanya $26,4 \%$. Responden paling banyak terpapar informasi PMK dari media elektronik internet $(44,7 \%)$, media sosial facebook $(32,0 \%)$, media cetak koran $(21,8 \%)$, media ilmiah seminar (52,3\%), dan perkuliahan (52,3\%). Responden yang pernah diskusi mengenai PMK dengan bidan lainnya $55,8 \%$, dengan perawat $8,6 \%$, dan dengan dokter $21,8 \%$.

Rata-rata jumlah skor pengetahuan mengenai PMK pada bidan di Kabupaten Musi Rawas Sumatera Selatan yaitu $14,04(95 \% \mathrm{Cl} 13,53-14,55)$ dengan standar deviasi 3,61. Nilai pengetahuan mengenai PMK terendah yaitu 5 dan nilai tertinggi 21 .

Tabel 3. Kepercayaan dan Keterpaparan Informasi Mengenai PMK pada Bidan di Kabupaten Musi Rawas Sumatera Selatan Tahun 2016 ( $n=197)$

\begin{tabular}{lcc}
\hline \multicolumn{1}{c}{ Variabel } & $\mathbf{n}$ & $\%$ \\
\hline $\begin{array}{l}\text { Kepercayaan terhadap perawatan } \\
\text { BBLR }\end{array}$ & 106 & 53,8 \\
$\begin{array}{l}\text { Keterpaparan informasi PMK dari } \\
\text { media elektronik }\end{array}$ & 132 & 67,0 \\
$\begin{array}{l}\text { Keterpaparan informasi PMK dari } \\
\text { media sosial }\end{array}$ & 93 & 47,2 \\
$\begin{array}{l}\text { Keterpaparan informasi PMK dari } \\
\text { media cetak }\end{array}$ & 125 & 63,5 \\
$\begin{array}{l}\text { Keterpaparan informasi PMK dari } \\
\text { pelatihan }\end{array}$ & 52 & 26,4 \\
$\begin{array}{l}\text { Keterpaparan informasi PMK dari } \\
\text { diskusi dengan tenaga kesehatan } \\
\text { lainnya }\end{array}$ & 120 & 60,9 \\
\hline
\end{tabular}

Pengetahuan mengenai PMK dikategorikan baik bila skor pengetahuan > 70\% (tabel 4). Responden yang mempunyai pengetahuan baik mengenai PMK sebanyak 39,6\%.
Rata-rata jumlah skor sikap responden terhadap PMK adalah 61,24 (95\% Cl 60,39-62,10) dengan standar deviasi 6,084. Skor terendah 39 dan skor tertinggi 78. Sikap terhadap PMK dikategorikan berdasarkan presentase jumlah skor sikap (70\%). Pada tabel 4 menunjukkan bahwa responden yang mempunyai sikap positif terhadap PMK sebanyak 89,3\%.

Rata-rata nilai pengetahuan responden pada masing-masing kategori yaitu definisi dan permasalahan pada BBLR $(65,57 \%)$, definisi PMK $(83,00 \%)$, manfaat PMK $(73,60 \%)$, dan pelaksanaan PMK (54,10\%). Pada tabel 5 diketahui bahwa hanya ada $20,8 \%$ responden yang menjawab benar pada pertanyaan batas suhu BBLR dikatakan mengalami hipotermi, selanjutnya hanya ada $32,0 \%$ yang menjawab benar pada pertanyaan syarat bayi yang telah dilakukan PMK boleh dipulangkan dan 32,5\% yang menjawab benar pada pertanyaan posisi yang benar saat bayi dilakukan PMK.

Tabel 4. Pengetahuan dan Sikap Terhadap Perawatan Metode Kanguru pada Bidan di Kabupaten Musi Rawas Sumatera Selatan Tahun 2016 ( $n=197$

\begin{tabular}{|l|c|c|}
\hline Variabel & $\mathbf{n}$ & $\%$ \\
\hline Pengetahuan Mengenai PMK & & \\
Kurang Baik (<70\%) & 119 & 60,4 \\
Baik ( $\geq 70 \%)$ & 78 & 39,6 \\
Sikap Terhadap PMK & & \\
Negatif (<70\%) & 21 & 10,7 \\
Positif ( $\geq 70 \%)$ & 176 & 89,3 \\
\hline
\end{tabular}


Tabel 5 Pengetahuan mengenai Perawatan Metode Kanguru pada Bidan di Kabupaten Musi Rawas Sumatera Selatan Tahun $2016(n=197)$

\begin{tabular}{|c|c|}
\hline Pertanyaan & $\begin{array}{c}\text { Benar } \\
(\%)\end{array}$ \\
\hline Definisi BBLR & 93,9 \\
\hline Ketahanan hidup BBLR & 88,3 \\
\hline Durasi pelaksanaan PMK & 87,8 \\
\hline Definisi PMK & 83,2 \\
\hline Manfaat PMK bagi ibu & 83,2 \\
\hline Manfaat PMK bagi bayi & 82,7 \\
\hline $\begin{array}{l}\text { Perawatan yang perlu dilakukan pada } \\
\text { BBLR }\end{array}$ & 80,2 \\
\hline Tanda-tanda bahaya pada BBLR & 76,6 \\
\hline Makanan terbaik untuk BBLR & 74,6 \\
\hline Cara memerah ASI & 70,1 \\
\hline $\begin{array}{l}\text { Jumlah nutrisi yang sebaiknya diberikan } \\
\text { pada BBLR }\end{array}$ & 70,1 \\
\hline $\begin{array}{l}\text { Pemberian nutrisi pada bayi yang } \\
\text { dirawat dengan PMK }\end{array}$ & 62,9 \\
\hline Penyebab bayi kehilangan panas tubuh & 59,4 \\
\hline $\begin{array}{l}\text { Permasalahan yang umumnya muncul } \\
\text { pada BBLR }\end{array}$ & 55,3 \\
\hline $\begin{array}{l}\text { Manfaat PMK dibanding perawatan } \\
\text { inkubator }\end{array}$ & 54,8 \\
\hline $\begin{array}{l}\text { Pemberian nutrisi pada bayi dengan } \\
\text { refleks menghisap yang masiih kurang } \\
\text { baik }\end{array}$ & 53,3 \\
\hline $\begin{array}{l}\text { Hal-hal yang menyebabkan bayi } \\
\text { kehilangan panas tubuh }\end{array}$ & 52,8 \\
\hline Pelaksanaan PMK & 51,3 \\
\hline $\begin{array}{l}\text { Dampak pemberian makanan lebih } \\
\text { awal pada BBLR }\end{array}$ & 38,1 \\
\hline $\begin{array}{l}\text { Posisi yang benar saat bayi dilakukan } \\
\text { PMK }\end{array}$ & 32,5 \\
\hline $\begin{array}{l}\text { Syarat bayi yang telah dilakukan PMK } \\
\text { boleh dipulangkan }\end{array}$ & 32,0 \\
\hline $\begin{array}{l}\text { Batas suhu BBLR dikatakan mengalami } \\
\text { hipotermi }\end{array}$ & 20,8 \\
\hline
\end{tabular}

Tabel 6. Sikap terhadap Perawatan Metode Kanguru pada Bidan di Kabupaten Musi Rawas Sumatera Selatan Tahun 2016 (n = 197)

\begin{tabular}{|c|c|}
\hline Pernyataan & $\begin{array}{c}\text { Sikap Positif } \\
(\%)\end{array}$ \\
\hline PMK mudah diterima & 98,0 \\
\hline Ibu merasa senang jika melakukan PMK & 97,5 \\
\hline $\begin{array}{l}\text { PMK memberi berbagai keuntungan } \\
\text { yang tidak bisa diberikan oleh inkubator }\end{array}$ & 95,9 \\
\hline PMK meningkatkan produksi ASI & 94,9 \\
\hline $\begin{array}{l}\text { Posisi kanguru sangat ideal dalam } \\
\text { proses menyusui }\end{array}$ & 94,9 \\
\hline PMK mudah dilakukan & 94,9 \\
\hline $\begin{array}{l}\text { Posisi bayi menempel pada kulit ibu } \\
\text { (skin to skin) dapat digunakan sebagai } \\
\text { rujukan ketika bayi dibawa pulang }\end{array}$ & 93,4 \\
\hline $\begin{array}{l}\text { PMK dapat digunakan untuk membawa } \\
\text { bayi saat dirujuk dari fasilitas kesehatan } \\
\text { ke rumah }\end{array}$ & 93,4 \\
\hline $\begin{array}{l}\text { PMK dapat meningkatkan berat badan } \\
\text { bayi BBLR }\end{array}$ & 91,9 \\
\hline $\begin{array}{l}\text { Kedua orangtua harus terlibat dalam } \\
\text { PMK }\end{array}$ & 91,4 \\
\hline $\begin{array}{l}\text { Petugas kesehatan harus memantau } \\
\text { PMK yang dilakukan oleh ibu di RS }\end{array}$ & 90,4 \\
\hline $\begin{array}{l}\text { PMK dapat dilakukan pada bayi berat } \\
1-1,8 \mathrm{~kg} \text { dengan kondisi stabil }\end{array}$ & 88,3 \\
\hline $\begin{array}{l}\text { Petugas kesehatan tidak dapat merawat } \\
\text { bayi lain dengan maksimal karena harus } \\
\text { fokus mengawasi Ibu melakukan PMK }\end{array}$ & 85,3 \\
\hline $\begin{array}{l}\text { PMK harus dimulai segera setelah bayi } \\
\text { lahir }\end{array}$ & 84,8 \\
\hline $\begin{array}{l}\text { PMK tidak sesuai dengan adat istiadat } \\
\text { di masyarakat }\end{array}$ & 80,2 \\
\hline $\begin{array}{l}\text { Kain khusus untuk melakukan PMK } \\
\text { susah didapatkan }\end{array}$ & 78,2 \\
\hline $\begin{array}{l}\text { Lebih mudah menggunakan inkubator } \\
\text { daripada PMK }\end{array}$ & 78,2 \\
\hline $\begin{array}{l}\text { PMK meningkatkan beban kerja tenaga } \\
\text { kesehatan }\end{array}$ & 76,1 \\
\hline $\begin{array}{l}\text { PMK lebih susah diterima oleh } \\
\text { masyarakat awam daripada inkubator }\end{array}$ & 58,9 \\
\hline $\begin{array}{l}\text { PMK hanya boleh dilakukan dengan } \\
\text { pengawasan petugas kesehatan }\end{array}$ & 54,8 \\
\hline
\end{tabular}


Pada tabel 6 menunjukkan bahwa sikap positif terhadap PMK paling sedikit terdapat pada pernyataan "PMK hanya boleh dilakukan dengan pengawasan petugas kesehatan" yaitu oleh $54,8 \%$ bidan setuju atau sangat setuju dengan pernyataan tersebut. Selanjutnya terdapat pada pernyataan "PMK lebih susah diterima oleh masyarakat awam daripada inkubator" oleh $58,9 \%$ responden dan pernyataan "PMK meningkatkan beban kerja tenaga kesehatan" oleh $76,1 \%$ responden setuju atau sangat setuju dengan pernyataan tersebut.

Hasil pemodelan terakhir (tabel 7) didapatkan bahwa ada tiga variabel independen yang berhubungan secara signifikan dengan pengetahuan tentang PMK yaitu kepercayaan terhadap perawatan BBLR, keterpaparan informasi PMK dari media ilmiah, dan keterpaparan informasi PMK dari pelatihan. Dari ketiga variabel tersebut, keterpaparan informasi PMK dari pelatihan paling dominan berhubungan dengan pengetahuan tentang $\mathrm{PMK}$ dengan $\mathrm{OR}=3,3$, artinya bidan yang pernah terpapar informasi PMK dari pelatihan mempunyai pengetahuan tentang PMK 3,3 kali lebih baik dibandingkan yang tidak pernah terpapar informasi PMK dari pelatihan, setelah dikontrol dengan variabel kepercayaan terhadap perawatan BBLR, keterpaparan informasi PMK dari media ilmiah, dan kepemilikan media cetak.

Hasil pemodelan terakhir (tabel 8) didapatkan bahwa keterpaparan informasi PMK dari pelatihan paling dominan berhubungan dengan sikap terhadap PMK pada bidan di Kabupaten Musi Rawas Sumatera Selatan dengan $O R=3,8$, artinya bidan yang pernah terpapar informasi PMK dari pelatihan mempunyai sikap terhadap PMK 3,8 kali lebih positif dibandingkan yang tidak pernah terpapar informasi PMK dari pelatihan, setelah dikontrol dengan variabel kepercayaan terhadap perawatan BBLR.

Tabel 7. Pemodelan Akhir Multivarat Pengetahuan tentang PMK

\begin{tabular}{|l|c|c|c|c|}
\hline Variabel & B & $\rho$ - value & OR & 95\% CI \\
\hline Kepercayaan & 0,871 & 0,027 & 2,4 & $(1,1-5,2)$ \\
Keterpaparan informasi dari media elektronik & $-0,429$ & 0,227 & 0,7 & $(0,3-1,3)$ \\
Keterpaparan informasi dari media sosial & 0,409 & 0,222 & 1,5 & $(0,8-2,9)$ \\
Keterpaparan informasi dari media cetak & 0,194 & 0,575 & 1,2 & $(0,6-2,4)$ \\
Keterpaparan informasi dari media ilmiah & 1,064 & 0,017 & 2,9 & $(1,2-6,9)$ \\
Keterpaparan informasi dari pelatihan & 1,183 & 0,001 & 3,3 & $(1,6-6,7)$ \\
Keterpaparan informasi dari diskusi dengan tenaga & $-0,091$ & 0,796 & 0,9 & $(0,5-1,8)$ \\
kesehatan lainnya & 0,910 & 0,009 & 2,5 & $(1,3-4,9)$ \\
Kepemilikan media cetak &
\end{tabular}


Tabel 8. Pemodelan Akhir Multivariat Sikap terhadap PMK

\begin{tabular}{|l|c|c|c|c|}
\hline \multicolumn{1}{|c|}{ Variabel } & B & p - value & OR & 95\%Cl \\
\hline Pengetahuan & $-1,001$ & 0,054 & 0,4 & $(0,1-1,0)$ \\
Kepercayaan & 0,690 & 0,325 & 2,0 & $(0,5-7,9)$ \\
Keterpaparan informasi dari media elektronik & $-19,752$ & 0,997 & 0,0 & $(0,0-0,0)$ \\
Keterpaparan informasi dari media sosial & $-0,062$ & 0,907 & 0,9 & $(0,3-2,6)$ \\
Keterpaparan informasi dari media cetak & 0,399 & 0,463 & 1,5 & $(0,5-4,3)$ \\
Keterpaparan informasi dari media ilmiah & 0,182 & 0,787 & 1,2 & $(0,3-4,5)$ \\
Keterpaparan informasi dari pelatihan & 1,347 & 0,049 & 3,8 & $(1,0-14,7)$ \\
Keterpaparan informasi dari diskusi dengan tenaga & 0,025 & 0,964 & 1,0 & $(0,3-3,1)$ \\
kesehatan lainnya & & & & \\
\hline
\end{tabular}

\section{PEMBAHASAN}

Menurut Rotter, kepercayaan adalah kecenderungan seseorang untuk yakin terhadap sesuatu atau orang lain. ${ }^{15}$ Pada penelitian ini, ada $19,8 \%$ bidan yang kepercayaan terhadap perawatan BBLRnya baik. Perawatan BBLR yang tidak disetujui oleh $72,6 \%$ bidan adalah semua BBLR tidak bisa menghisap dengan baik dan $67,5 \%$ bidan juga tidak setuju bahwa BBLR perlu minum dari botol susu supaya belajar menghisap. Hal ini sesuai dengan teori bahwa menurut Newman, bayi BBLR dapat belajar menghisap secara alami, tidak perlu diajarkan dengan menggunakan botol. Bayi tidak memerlukan botol untuk belajar menyusu. Pelaksanaan metode kanguru dan mengenalkan bayi pada payudara ibunya segera dapat membantu bayi belajar menghisap. ${ }^{16}$

Bidan yang kepercayaan terhadap perawatan BBLR kurang baik ada sebanyak $80,2 \%$. Perawatan BBLR yang paling banyak disetujui oleh bidan $80,7 \%$ adalah BBLR perlu diberikan bedong yang lebih tebal jika terjadi hipotermi dan $71,6 \%$ setuju bahwa perawatan BBLR bisa dilakukan dengan penggunaan botol air panas di dekat bayi. Hal ini tidak sesuai dengan teori bahwa menurut Depkes $\mathrm{RI}$, penanganan bayi yang mengalami hipotermi dapat dilakukan dengan mengganti baju yang basah dan dingin dengan pakaian yang hangat, memakaikan topi dan selimut yang hangat. Apabila ada ibu atau pengganti ibu, bayi dihangatkan dengan melakukan kontak kulit dengan kulit (perawatan metode kanguru), tetapi apabila ibu tidak ada, bayi dihangatkan dengan incubator. ${ }^{17}$

Kepercayaan perawatan BBLR yang kurang baik pada bidan bisa disebabkan karena kurangnya pengetahuan bidan mengenai perawatan BBLR. Peningkatan pengetahuan bidan mengenai perawatan BBLR terutama dengan metode kanguru sangat diperlukan agar bidan lebih mengetahui perawatan BBLR yang sesuai dengan kemajuan ilmu kedokteran terkini. Peningkatan pengetahuan mengenai perawatan metode kanguru bisa dilakukan dengan diadakannya seminar-seminar ilmiah dan juga pelatihan tentang PMK agar bidan dapat memberikan KIE mengenai perawatan BBLR dengan metode kanguru kepada ibu yang dideteksi hamil dengan BBLR sehingga ibu dan keluarga bisa merawat BBLR dengan baik.

Keterpaparan informasi PMK pada bidan di Kabupaten Musi Rawas paling banyak berasal dari media ilmiah (79,2\%). Media ilmiah yang menjadi sumber informasi PMK paling banyak yaitu dari seminar (52,3\%) dan juga dari perkuliahan (52,3\%). Keterpaparan informasi PMK pada bidan paling sedikit dari pelatihan yaitu hanya $26,4 \%$ bidan yang pernah terpapar informasi PMK dari pelatihan PMK. 
Jumlah bidan yang telah mengikuti pelatihan PMK masih sedikit, sejalan dengan penelitian Dalal yang menunjukkan bahwa tenaga kesehatan di Ahmedabad, India, yang baru mengikuti pelatihan PMK sebanyak $48,49 \%^{18}$. Sedikitnya jumlah bidan yang telah mengikuti pelatihan PMK dimungkinkan karena mahalnya biaya pelatihan yang harus ditanggung bidan secara individu dan akses pelatihan PMK yang tidak mudah. Berdasarkan data dari website Perinasia (2016), biaya pelatihan PMK di Jakarta sebesar dua juta rupiah ${ }^{19}$. Selain itu, bidan juga harus menanggung biaya transportasi secara individu. Kerja sama antara pemerintah dengan organisasi profesi bidan sangat diperlukan untuk memfasilitasi pelatihan PMK kepada bidan. Pelatihan PMK bisa dilakukan di daerah setempat dan juga bisa digabungkan dengan pelatihanpelatihan lainnya yang diperlukan bidan untuk mengurangi biaya yang diperlukan.

Pengetahuan tentang perawatan metode kanguru merupakan domain yang sangat penting dalam membentuk praktik pelaksanaan metode kanguru. Bidan yang mempunyai pengetahuan baik tentang PMK di Kabupaten Musi Rawas sebanyak 39,6\%. Hasil ini sesuai dengan penelitian Dalal yang juga menemukan bahwa hanya ada $25,81 \%$ tenaga kesehatan di Ahmedabad yang mempunyai pengetahuan baik mengenai $\mathrm{PMK}^{18}$. Pengetahuan yang kurang bisa disebabkan karena pengalaman yang kurang. Pengalaman berhubungan dengan pengetahuan seseorang. Seseorang yang mempunyai pengalaman banyak akan menambah pengetahuannya. Tenaga kesehatan di Ahmedabad dan bidan di Kabupaten Musi Rawas mempunyai pengetahuan yang kurang baik mengenai PMK, bisa disebabkan karena pengalaman yang kurang dalam praktek perawatan metode kanguru pada BBLR. Implementasi PMK di Indonesia memang masih terdapat hanya di RS. Belum sampai pada pemantauan PMK oleh bidan di rumah sesudah pulang dari RS, sehingga pengalaman bidan dalam praktek PMK masih kurang.
Pengetahuan bidan yang sudah baik pada item pertanyaan definisi dan permasalahan BBLR, definisi PMK, dan manfaat PMK. Jika dibandingkan dengan penelitian Dalal, pengetahuan bidan di Kabupaten Musi Rawas sudah lebih baik karena pada penelitian Dalal, hanya $32,4 \%$ tenaga kesehatan yang mempunyai pengetahuan benar mengenai BBLR. Namun pada materi pelaksanaan dan komponen-komponen PMK, hanya ada $54,10 \%$ bidan di Kabupaten Musi Rawas yang menjawab benar dan pada penelitian Dalal juga hanya 33,1\% yang menjawab benar mengenai pelaksanaan dan komponenkomponen PMK. ${ }^{18} \mathrm{Hal}$ ini menunjukkan bahwa pengetahuan mengenai PMK pada bidan masih sebatas definisi dan manfaat PMK, belum sampai pada pelaksanaan PMK.

Pada penelitian Marliyani menunjukkan bahwa 62,5\% tenaga kesehatan di ruang perinatologi RSUD Banjarbaru sudah mempunyai pengetahuan yang baik mengenai $\mathrm{PMK}^{20} \mathrm{Hal}$ ini bisa disebabkan karena RSUD Banjarbaru sudah mengimplementasikan PMK di ruang perinatologinya sehingga tenaga kesehatannya sudah mempunyai pengalaman praktek PMK dan mempunyai pengetahuan yang lebih baik mengenai PMK. Hal ini sesuai dengan penelitian Strand yang menunjukkan adanya perbedaan yang signifikan antara unit $A$ dan unit $B$ ruang perinatologi. Unit $A$ mempunyai pengetahuan yang lebih baik mengenai PMK daripada unit $B$. Hasil analisis pertanyaan terbuka menjelaskan bahwa di unit $B$ memang belum diterapkan PMK untuk perawatan BBLR, sedangkan di unit $B$ sudah diterapkan PMK. ${ }^{21}$

Sikap terhadap PMK pada bidan di Kabupaten Musi Rawas sudah lebih banyak yang positif yaitu sebanyak $89,3 \%$. Sikap negatif hanya sebanyak $10,7 \%$ dan ditunjukkan pada beberapa pernyataan saja yaitu $45,2 \%$ pada pernyataan "PMK hanya boleh dilakukan dengan pengawasan petugas kesehatan" dan $41,1 \%$ pada pernyatan "PMK lebih susah diterima oleh masyarakat awam daripada inkubator". 
Menurut WHO, PMK bisa tetap diteruskan oleh ibu bayi di rumah setelah ibu dan bayi pulang dari rumah sakit tanpa ada pengawasan tenaga kesehatan di rumah. Bidan atau perawat rumah sakit memang perlu mengevaluasi kemampuan ibu dalam melaksanakan PMK sebelum pulang ke rumah dan melakukan pemantuan secara teratur untuk melakukan follow-up pelaksanaan PMK. ${ }^{22}$

Sikap positif terhadap PMK pada bidan di Kabupaten Musi Rawas lebih banyak ditunjukkan. Sebanyak 94,9\% bidan mempunyai sikap positif atau setuju bahwa PMK sangat ideal dalam proses menyusui dan dapat meningkatkan produksi ASI. Sikap bidan pada penelitian ini menunjukkan hasil yang lebih positif dibandingkan pada penelitian Dalal yang menunjukkan hanya $27,6 \%$ tenaga kesehatan di Ahmedabad yang setuju bahwa PMK dapat meningkatkan proses menyusui. ${ }^{18}$ Menurut Priya, perawatan metode kanguru memang dapat meningkatkan produksi ASI dan mempermudah pemberian ASI dari ibu ke bayinya. ${ }^{10}$ Menurut penelitian Flacking, PMK justru dapat meningkatkan pengaruh pada proses menyusui terutama pada lama menyusui. ${ }^{23}$

Sikap positif terhadap PMK pada bidan juga ditunjukkan pada pernyataan bahwa PMK harus segera dimulai setelah bayi lahir (84,8\%). Pada penelitian Dalal (2014), hanya ada sebanyak $28,3 \%$ tenaga kesehatan di Ahmedabad yang setuju bahwa PMK seharusnya dimulai segera setelah bayi lahir ${ }^{18}$. PMK merupakan perawatan pada BBLR dengan melakukan kontak langsung antara kulit ibu dengan kulit bayi (skin to skin contact) ${ }^{22}$. Prinsip PMK hampir sama dengan Inisiasi Menyusu Dini (IMD) yang seharusnya dimulai segera setelah bayi lahir.

Sikap bidan terhadap PMK di Kabupaten Musi Rawas didapatkan hasil yang lebih positif. Hal ini bisa disebabkan karena pengambilan sampel pada penelitian ini menggunakan responden bidan yang hadir di seminar "Filosofi Terkini Perawatan Bayi BBLR dan Prematur". Bidan yang sudah hadir dalam seminar berarti menunjukkan bahwa memang sudah mempunyai sikap yang positif mengenai PMK.

Hasil analisis multivariat pada penelitian ini didapatkan bahwa ada hubungan yang signifikan antara kepercayaan terhadap perawatan BBLR, keterpaparan informasi dari media ilmiah dan pelatihan dengan pengetahuan tentang PMK pada bidan di Kabupaten Musi Rawas Sumatera Selatan. Kepercayaan adalah kecenderungan seseorang untuk yakin terhadap sesuatu atau orang lain. Kepercayaan yang kurang baik bisa karena keterbatasan pengetahuan dan keterbatasan penalaran. Pada penelitian ini menggunakan desain penelitian cross sectional, sehingga tidak diketahui urutan yang lazim antara kepercayaan dan pengetahuan. Kepercayaan bidan terhadap perawatan BBLR yang kurang baik bisa dimungkinkan disebabkan karena keterbatasan pengetahuan bidan mengenai PMK yang hanya sampai definisi dan manfaat PMK, belum sampai pada pelaksanaan PMK. Oleh karena itu peningkatan pengetahuan bidan mengenai PMK dari berbagai media baik media elektronik, media sosial, media ilmiah, maupun dari pelatihan sangat diperlukan.

Perawatan metode kanguru memang sudah sering menjadi topik kajian-kajian ilmiah seperti seminar, simposium, dan workshop. Ikatan Bidan Indonesia Cabang Musi Rawas juga telah mengadakan seminar filosofi terkini perawatan bayi prematur dan BBLR yang membahas tentang perawatan metode kanguru pada bulan Maret 2016.

Perawatan metode kanguru juga sudah masuk ke dalam materi perkuliahan kurikulum pendidikan Diploma 3 kebidanan. Perawatan metode kanguru menjadi salah satu materi yang dibahas dalam mata kuliah asuhan kebidanan neonatus, bayi, balita, dan anak pra sekolah ${ }^{23}$. Banyaknya seminar mengenai PMK dan masuknya PMK ke dalam kurikulum pendidikan kebidanan dapat meningkatkan kesadaran dan pengetahuan bidan mengenai PMK. 
Hasil analisis multivariat juga menunjukkan bahwa variabel yang paling dominan berhubungan dengan pengetahuan tentang PMK adalah keterpaparan informasi PMK dari pelatihan PMK. Hasil penelitian ini sejalan dengan penelitian Dalal yang juga menunjukkan hubungan yang signifikan antara status pelatihan PMK dengan pengetahuan tentang PMK. ${ }^{18}$ Pengaruh pelatihan PMK terhadap pengetahuan tentang PMK pada bidan juga ditunjukkan pada penelitian Ayunin yang menyatakan adanya peningkatan pengetahuan tentang PMK sebesar $30,61 \%$ antara pretest dan posttest pelatihan PMK pada bidan desa di wilayah kerja Puskesmas Sawit dan Puskesmas Ngemplak Boyolali. ${ }^{25}$

Hasil analisis multivariat pada penelitian ini didapatkan bahwa variabel yang paling dominan berhubungan dengan sikap terhadap PMK pada bidan yaitu variabel keterpaparan informasi PMK dari pelatihan PMK. Keterpaparan informasi PMK dari media massa dan media ilmiah juga mempengaruhi sikap terhadap PMK namun kurang berhubungan secara signifikan. Media massa termasuk media elektronik, sosial, dan cetak merupakan saluran media massa yang menjangkau khalayak dalam jumlah banyak. ${ }^{26}$ Media ilmiah termasuk seminar dan perkuliahan yang merupakan sumber keterpaparan informasi mengenai PMK pada bidan (52,3\%) juga menjangkau peserta/komunikan yang jumlahnya banyak.

Media dengan komunikan yang banyak efisien hanya untuk memperkenalkan suatu inovasi kepada khalayak yang banyak, namun tidak efektif untuk mempersuasi individu. Berbeda dengan pelatihan yang pesertanya lebih sedikit daripada seminar atau perkuliahan. Pelatihan termasuk saluran komunikasi interpersonal. Saluran komunikasi interpersonal lebih efektif dalam mempersuasi individu untuk menerima suatu inovasi, terutama apabila ada kesamaan status dari kedua pihak baik dari informan maupun komunikannya, seperti status sosial, ekonomi, atau pendidikan. Saluran komunikasi interpersonal lebih tepat digunakan untuk mengubah sikap atau bahkan perilaku penerima secara personal. ${ }^{26}$

Pengambilan data dalam penelitian ini dilakukan oleh dua orang peneliti dengan jumlah bidan yang hadir dalam seminar "Filosofi Terkini Perawatan Bayi Prematur dan BBLR" \pm 250 orang, sehingga peneliti tidak dapat mengontrol keseluruhan proses dalam pengisian kuesioner masing-masing individu yang memungkinkan adanya diskusi antara responden satu dengan yang lainnya. Hal tersebut merupakan keterbatasan dalam penelitian ini.

Pengambilan data dalam penelitian ini juga menggunakan kuesioner yang diisi sendiri oleh responden, sehingga kebenaran data bergantung pada kejujuran responden. Ada beberapa pertanyaan dalam kuesioner yang menanyakan keterpaparan informasi PMK dalam 6 bulan terakhir dan 5 tahun terakhir sehingga ada kemungkinan bias yang disebabkan karena ingatan responden.

\section{KESIMPULAN}

Kepercayaan terhadap perawatan BBLR pada bidan masih kurang baik. Bidan paling banyak terpapar informasi PMK dari media elektronik. Bidan yang terpapar informasi PMK dari pelatihan masih sedikit yaitu hanya $26,4 \%$. Sedikitnya bidan yang sudah mengikuti pelatihan PMK bisa disebabkan karena mahalnya biaya pelatihan yang ditanggung bidan sendiri. Bidan yang mempunyai pengetahuan baik tentang PMK masih sedikit $(39,6 \%)$, namun yang mempunyai sikap positif terhadap PMK sudah lebih banyak $(89,3 \%)$.

Keterpaparan informasi PMK dari pelatihan paling dominan berhubungan dengan pengetahuan dan sikap terhadap PMK. Bidan yang pernah terpapar informasi PMK dari pelatihan mempunyai pengetahuan tentang PMK 3,3 kali lebih baik dibandingkan yang tidak pernah terpapar 
informasi PMK dari pelatihan. Bidan yang pernah terpapar informasi PMK dari pelatihan mempunyai sikap terhadap PMK 3,8 kali lebih positif dibandingkan yang tidak pernah terpapar informasi PMK dari pelatihan.

\section{SARAN}

Diperlukan kerja sama antara Dinas Kesehatan dan IBI Kabupaten Musi Rawas untuk meningkatkan pengetahuan bidan pada pelayanan perinatal khususnya perawatan BBLR dengan metode kanguru dengan cara memfasilitasi pelatihan PMK kepada bidan. Pelatihan PMK bisa digabungkan dengan pelatihan-pelatihan lainnya yang dianggap penting bagi pelayanan kesehatan maternal perinatal untuk mengurangi biaya pelatihan.

Meningkatkan pengetahuan diri mengenai PMK dengan cara mengikuti seminar-seminar ilmiah dan juga pelatihan PMK agar nantinya dapat memberikan KIE mengenai definisi, manfaat, dan cara pelaksanaan PMK kepada ibu hamil dengan BBLR, serta meningkatkan implementasi PMK baik di rumah sakit maupun di rumah bagi ibu dengan BBLR yang sudah pulang dari rumah sakit.

Bagi peneliti selanjutnya sebaiknya meneliti lebih lanjut mengenai pengetahuan dan sikap bidan terhadap perawatan metode kanguru baik di Kabupaten Musi Rawas Sumatera Selatan maupun di tempat lain dengan menggunakan sistem random sampling agar dapat mewakili seluruh populasi. Penelitian lebih lanjut juga perlu dilakukan untuk melihat efek pengetahuan dan sikap dengan praktek PMK pada bidan yang sudah diberikan pelatihan PMK.

\section{DAFTAR PUSTAKA}

1. Nursinih. 2012. Pengaruh Pelaksanaan Perencanaan Pulang Berfokus Perawatan Metode Kanguru (PMK) terhadap Keterampilan Ibu Melakukan PMK di Rumah. Tesis: Fakultas IImu Keperawatan Universitas Indonesia.
2. WHO. 2016. Trends in Infant Mortality Rate (Per 1000 Live Births) Globally and by WHO Region (1990-2015). Diakses pada tanggal 6 Maret 2016 (online).http://www.who.int/gho/child_health/ mortality/neonatal_infant/en

3. BPS (Badan Pusat Statistik), BKKBN (Badan Kependudukan dan Keluarga Berencana Nasional), Kemenkes (Kementerian Kesehatan RI), ICF Internasional. 2013. Survey Demografi dan Kesehatan Indonesia 2012. Jakarta: BPS, BKKBN, Kemenkes RI, dan ICF internasional.

4. Dinas Kesehatan Provinsi Sumatera Selatan. 2015. Profil Kesehatan Provinsi Sumatera Selatan Tahun 2014. Palembang.

5. WHO. 2016. Newborns: Reducing Mortality. Diakses tanggal 6 Maret 2016 (online). http://www.who. int/mediacentre/factsheets/fs333/en

6. Sloan NL., Ahmed S., Mitra SN., Choudhury N., Chowdhury M., Rob U., Winikoff B. 2008. Community- Based Kangaroo Mother Care to Prevent Neonatal and Infant Mortality: A Randomized Controlled Cluster Trial. Pediatrics Vol. 121. No. 5: 1047-1059. http://pediatrics.aap publications.org/content/121/5/e1047.long

7. Depkes RI. 2008. Perawatan Bayi Berat Badan Rendah dengan Metode Kanguru. Jakarta: Departemen Kesehatan Republik Indonesia.

8. Johnson JG, Mwebesa W, Abwao S, Ganges F, Narayanan I, Moran A, Baqui A, Kerber K, Mazia G, Wall S, Standley J. 2012. Kangaroo Mother Care Implementation Guide. Washington

9. Dinas Kesehatan Kabupaten Musirawas. 2016. Resume Profil Dinas Kesehatan Kabupaten Musi Rawas Tahun 2015. (Tidak dipublikasikan).

10. Priya, J. J. 2004. Kangaroo Care for Low Birth Weight Babies. Nursing Journal of India Vol. 95 No. 9: 209-212. https://www.researchgate.net / publication/7898768_Kangaroo_care_for_low_ birth_weight_babies

11. Deswita. 2011. Pengaruh Perawatan Metode Kanguru terhadap Respons Fisiologis Bayi Prematur. Jurnal Kesehatan Masyarakat Nasional. Vol 5 No. 5. http://jurnalkesmas.ui.ac.id/index.php /kesmas/ article/view/131/132

12. Lawn J.E., Kambafwile J.M., Horta B.L., Barros F.C., Cousen S. 2010. Kangaroo Mother Care to Prevent Neonatal Deaths Due To Preterm 
Birth Complications. International journal of Epidemiology. 39: 144-154. http://www.ncbi.nlm. nih.gov/pmc/articles/PMC2845870/

13. Pratomo, Hadi. 2014. Review of Kangaroo Mother Care in Indonesia 1997-2014. Depok: Faculty of Public Health.

14. Sembiring MB, Arief YS, Kristiawati. 2015. The Improvement of Knowledge and Skill Nurses in The Kangaroo Mother Care Method for Low Birth Weight Infants through Counseling. Pediomaternal Nursing Journal Vol 3. No. 2: 250-259. http:// journal.unair.ac.id/the-improvement-of-know ledge-and-skill-sofnursesinthe-kangaroo-mothercare-method-for-low-birth-weight-infants-throughcounseling-article-9587-media-130-category-.html

15. Rotter JB. 1971. Generalized Expectancies for Interpersonal Trust. Anner Phsychologist. Vol 26. No. 5: 443-452.

16. Newman, Jack . (2009). Menyusui Bayi Prematur. International Breastfeeding Centre. Diakses tanggal 30 Mei 2016 (online). http://nbci.ca/index. php?option=com_content $\&$ view=article $\& i d=358$ : breastfeeding-the-premature-baby-indo \& catid $=29$ : in formation-indonesian\&/temid=67

17. Depkes RI. 2009. Pedoman Pelayanan Kesehatan Bayi Berat Badan Rendah (BBLR) dengan Perawatan Metode Kanguru di Rumah Sakit dan Jejaringnya. Jakarta: Departemen Kesehatan Republik Indonesia.

18. Dalal A, Bala DV, Chauhan S. 2014. A Cross-Sectional Study on Knowledge and Attitude Regarding Kangaroo Mother Care Practice Among Health Care Providers in Ahmedabad District. International Journal of Medical Science and Public Health. Vol 3. Issue 3:253-256. http://www.scopemed.org/ fulltextpdf.php?mno=48 446

19. Perinasia. 2016. Pelatihan Manajemen BBLR dengan Metode Kanguru. Diakses pada tanggal 30 Mei 2016 (online). http://www.perinasia.com/ kegiatan/141.
20. Marliyani, Lina. 2010. Gambaran Pengetahuan dan Sikap Tenaga Kesehatan terhadap Pelaksanaan Metode Kanguru di Ruang Perinatologi RSUD Banjarbaru Tahun 2010. Akademi Kebidanan Martapura Yayasan Korpri Kabupaten Banjar.

21. Strand, Hedvig. 2011. Knowledge of and attitudes to the practice of Kangaroo Mother Care (KMC) among staff in two neonatal units. Uppsala Universitet. Diakses tanggal 20 Maret 2016. http://www.divaportal.se/smash/get/diva2:485881/ FULLTEXT01. pdf

22. WHO. 2003. Kangaroo Mother Care A Practical Guide. Geneva: Departement of Reproductive Health and Research

23. Flacking $\mathrm{R}$, Ewald $\mathrm{E}$, Wallin L. 2011. Positive Effect of Kangaroo Mother Care on Long-term Breastfeeding in Very Preterm Infant. JOGNN Vol 40, Issue 2: 190-197. http://www.pqcnc.org/docu ments/milkncccdoc/PQCNCHM PositiveeffectSTS BreastfeedingPreterm.pdf

24. Kemenkes RI. 2013. Kurikulum D-III Pendidikan Tenaga Kesehatan. Pusat Pendidikan dan Pelatihan Tenaga Kesehatan. Jakarta: Kementerian Kesehatan RI.

25. Ayunin, Elia Nur. (2015). Evaluasi Pelatihan Kombinasi Manajamen Laktasi dan Perawatan Metode Kanguru (PMK) pada Bidan di Desa di Wilayah Kerja Puskesmas Sawit dan Puskesmas Ngemplak. Tesis: Fakultas Kesehatan Masyarakat Universitas Indonesia.

26. Lestari, Widiyanti S. 2012. Evaluasi Penggunaan Saluran Komunikasi Antarpribadi Sebagai Salah Satu Strategi Komunikasi dalam Proses Adopsi Inovasi Program Pemerintah (Studi Kasus: Program Keluarga Harapan). Tesis: Program Pascasarjana Ilmu Komunikasi Universitas Indonesia. 